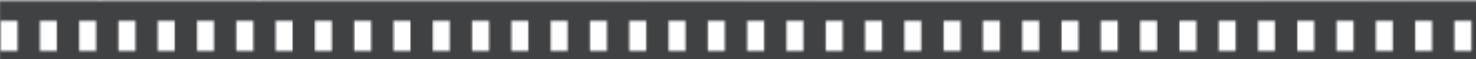

\section{Cinco hipóteses sobre o fotojornalismo em cenários de convergência}

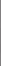

José Afonso da Silva Junior 


\title{
Cinco hipóteses sobre o fotojornalismo em cenários de convergência *
} Five hypotheses about photojournalism in convergence scenes

\author{
JoséAfonso da Silva Junior **
}

Resumo: O cenário de profundas alterações proporcionado pela convergência digital desdobra-se sobre a cadeia produtiva da fotografia de notícia. Problematizamos essa atividade através de etapas sucessivas de modo a categorizar o que seria ofotojornalismo em tempos de convergência. A partir desse patamar, trabalham-se cinco hipóteses gerais de como se articulam pontos chave na produção do fotojornalismo contemporâneo. Por fim, essas hipóteses são revisitadas criticamente em função de exemplos empíricos relacionados com a justaposição entre fotojornalismo e convergência digital.

Palavras-chave: Fotojornalismo. Convergência digital. Rotinas de trabalho no fotojornalismo.

\begin{abstract}
The scene of deep changes provided by the digital convergence shows its results in the supply chain of news photograph. The article raises doubts about this activity by a succession of steps, classifying what could photojournalism be at convergence times. From this level, five general hypotheses are formulated, showing how key points articulate with the production of contemporary photojournalism. Finally, these hypotheses are critically revisited in the light of empirical examples related to the juxtaposition of photojournalism and digital convergence.
\end{abstract}

Keywords: Photojournalism. Digital convergence. Work routines in photojournalism.

\footnotetext{
* Trabalho apresentado ao Grupo de Trabalho "Estudos de Jornalismo", do XX Encontro Nacional da Compós - Associação Nacional dos Programas de Pós-Graduação em Comunicação, realizado na Universidade Federal do Rio Grande do Sul (UFRGS), em Porto Alegre (RS), em junho de 2011. ** Pesquisador e professor adjunto do Programa de Pós-Graduação em Comunicação da Universidade Federal de Pernambuco (PPGCOM/UFPE). E-mail: zeafonsojr@gmail.com
} 


\section{Introdução}

Em um texto de 1901, Charles H. Caffin relatou que, ante a invenção da fotografia, o pintor francês Paul Delaroche declarou: "A partir de hoje a pintura está morta." Hoje, 110 anos depois, parece haver um interesse não só pela morte da fotografia, como do fotojornalismo. O que parece estar em xeque é não somente o estatuto documental da imagem fotográfica em si, como também a estabilidade da profissão de fotojornalista diante do violento conjunto de modificações pelo qual passou a profissão na última década. Ritchin, $(1990,2010)$ fala que a fotografia está minada no seu status de forma visual intrinsecamente veraz e Mitchell (1994), ainda na data do sesquicentenário da fotografia, em 1989, afirmava que a fotografia já estava morta, ou mais concretamente, radical e permanentemente deslocada.

O problema do campo mais geral da fotografia, e sua repetida e anunciada morte pelos teóricos de vertentes pós-modernas (FONTCUBERTA, 1997, 2010; GREEN, 2007; LISTER, 1997), também se manifesta, amiúde, no fotojornalismo. Matá-lo, preferencialmente de forma sumária e sem levar em conta as implicações, parece ser uma urgente necessidade. Desse arrebato recorrente de morbidade podem extrair-se duas preocupações relacionadas. A primeira decorrente da generalização de ordem digital que recai sobre a cadeia produtiva da fotografia. São os desdobramentos dos novos hábitos de relação com esses conteúdos simbólicos, naquilo que Jenkins (2008) genericamente define como cultura da convergência.

A questão evidente é diretamente vinculada a uma hipotética ambiguidade diante da imagem, que teria cada vez menos a capacidade de cumprir o seu contrato civil (AZOULAY, 2010) com a objetividade. Se essa é uma ameaça mais geral do campo da fotografia, outras mudanças são mais específicas advindas do campo do fotojornalismo. Como todo processo que revoluciona seu conjunto de rotinas, no mesmo movimento podem ser percebidos tanto os processos de inovação, como suas ambiguidades e contradições. 


\section{Do fotojornalismo digital ao de convergência: três estágios classificatórios}

A chegada da fotografia digital nas redações se deu de modo progressivo. Começou no início dos anos 1990 e se consolidou em meados da década de 2000. Nesse percurso, a adoção se deu de maneira escalonada. Durante um tempo razoável, conviveram processos híbridos entre a tecnologia analógica e a digital. (BAPTISTA, 2000; FERREIRA, 2002; CORRÊA, 2001; GIACOMELLI, 2000). Foi também um momento em que se mapeou uma sobreposição de domínios cognitivos entre os fotógrafos, divididos pela questão da geração, tempo de profissão e idade.

No caso do fotojornalismo, tratou-se de um momento tipicamente de migração de um conjunto de rotinas advindas de uma cadeia de produção inspirada e determinada pela lógica do suporte impresso, e sua conciliação ao conjunto de dispositivos e sistemas de ordem digital. Foi um momento entre dois mundos, duas perspectivas de relação com a imagem e um convívio que, se não tinha data certa para terminar, certamente sinalizava com uma morte anunciada. Foi, também, um renascimento.

Em paralelo à generalização dos recursos digitais aplicados à fotografia, a segunda preocupação advém justamente de uma perspectiva de fundo epistemológico. Ou seja, a adaptação a rotinas que, na verdade, falam de um horizonte mais amplo, com mudanças de maior alcance nos âmbitos da ética, do conhecimento, da cultura e, destarte, dos desdobramentos que isso reflete na ponta do processo, ou seja, na consolidação de habilidades, códigos, procedimentos rotinas e fluxos de trabalho.

Deste modo, pensar o fotojornalismo como percurso e não como algo estático é uma maneira de driblar a morte. Ao menos, a morte do fotojornalismo! A chave é pensar a prática como a manutenção de uma função central: a representação e obtenção de imagens vinculadas às notícias. Combinável, por sua vez, a estruturas tecnológicas mais amplas 
com a qual dialoga constantemente, adaptando-se, rearranjando a cadeia produtiva onde se insere. (SILVA JUNIOR, 2008).

Neste sentido, podemos colocar que, na escala de operação da fotografia digital aplicada ao fotojornalismo, detectamos três etapas principais no que concerne ao seu conjunto de práticas. Como delimitação metodológica opta-se pelo período posterior ao surgimento da fotografia digital nos jornais, não desprezando obviamente o largo conjunto de elementos que, neste mesmo momento de corte, estão presentes e se formaram de acordo com influências do próprio percurso histórico do fotojornalismo.

A primeira etapa, de transição, seria pré-adptativa, ou seja, quando o cenário de práticas correspondia à coexistência de sistemas de imagem e rotinas baseados numa interoperabilidade entre o digital e a analógica. É um modelo baseado entre bases tecnológicas diferentes - analógica e digital - e permeado por uma série de dispositivos de tradução entre essas bases de modo a manter a rotina de trabalho, como, por exemplo, scanners, modems, reveladores etc. Vale perceber que esse momento corresponde também à convivência de profissionais formados na fotografia analógica com os primeiros fotógrafos em bases digitais. Nesse momento, os fotógrafos não possuíam a polivalência do domínio tecnológico, restringindo-se a atividades do entorno fotográfico, como revelar, ampliar e editar o material visualmente e não necessariamente a predominância de esforços cooperativos para a produção de materiais visuais de maior complexidade. Note-se, ainda, que a produção geralmente era orientada para veículos impressos e, no máximo, para a internet, não havendo a predominância de integração da fotografia com materiais em multimídia.

A segunda etapa, que conclui o período de transição é a que denominamos adaptativa. Nela, o conjunto de práticas se caracteriza pela total eliminação de dispositivos de ordem analógica; o desaparecimento do filme como suporte de captação e do fim da fotografia em papel nas editorias de fotografia. Não se trabalha mais com a perspectiva de coexistência entre bases analógicas e digitais. Há uma predominância no corpo profissional de fotógrafos já adaptados ao fluxo 
de trabalho digital e com polivalência operacional, sendo, portanto, capazes de, além de dominar os dispositivos do entorno fotográfico, ter competência com sistemas de ordem informacional, como, por exemplo, a ingestão, transmissão, catalogação, tratamento e armazenamento de imagens. É o caso em que não só o estatuto da singularidade do fotógrafo passa a ser um analista e construtor de sistemas que integra as tecnologias fotográficas com as digitais.

Ainda na etapa adaptativa não se observa, como tendência predominante, a presença de esforços cooperativos ou coletivos para uma determinada cobertura, ou como modelo de trabalho. Assim, o direcionamento para a produção multimídia e multiplataforma se dá de modo esparso e assistemático.

A terceira etapa, a denominamos de convergente. Em que pese que não exista uma definição única sobre o conceito (SALAVERRIA, 2010, p.43), adotamos dois prismas principais: o primeiro, presente nas dinâmicas internas da redação que pressupõe a justaposição empresarial (fusão de empresas, por exemplo); tecnológica (adoção de dispositivos capazes de lidar com multitarefas); de plataformas (produzir um mesmo núcleo de conteúdo para vários meios); e profissional (o fotógrafo, no caso, tem capacidade de atuar com outras competências). O segundo prisma seria de ordem cultural, onde a cadeia de produção é concebida como um processo que afeta tanto o modo de produção do conteúdo como o seu consequente consumo. (JENKINS, 2008).

\section{Externalidades do processo da fotografia em modelo de convergência}

Destarte, aproximando a questão para o que seria a delimitação do fotojornalismo convergente, teríamos todas as características da etapa adaptativa potencializadas. Ou seja, a presença de fotógrafos que jamais usaram filme, a orientação editorial no sentido do uso regular de fotografia 
e vídeo - recurso hoje existente nas câmeras profissionais - e a demanda por uma necessária polivalência profissional, capaz de lidar com sistemas fotográficos e digitais. As maiores mudanças, contudo, ocorrem na consolidação e aceitação da edição do material em formato multimídia; a produção para outras plataformas e meios de modo regular e a geração de externalidades no contexto do trabalho ${ }^{1}$.

A respeito das externalidades configuradas, podemos no momento atual detectar duas resultantes. A primeira, na criação de alternativas que hibridizam o fotojornalismo como estrutura de discurso, porém não necessariamente atreladas a estruturas editoriais ${ }^{2}$. Dentro desse viés, há ainda a diversificação e criação de alternativas, por exemplo, no modo de financiamento de projetos. Vale mencionar fenômenos como o crowdfunding ${ }^{3}$. Trata-se uma ação coletiva em rede que busca, por meio de cooperação, atenção e confiança, arrecadar recursos, geralmente por meio da internet, para apoiar esforços iniciados por outras pessoas, instituições ou organizações. Com origem na própria ideia de caridade, já é um modelo operativo na indústria da música e hoje está recebendo atenção renovada para a fotografia, visto que as redes sociais, as comunidades online e os sistemas de micropagamentos facilitam o recebimento e a gestão dos recursos, além de estreitarem os laços entre os participantes e os doadores. São arranjos, presentes em iniciativas como os projetos Flattr, Latitude e Emphas.is ${ }^{4}$, que se propõem a abordar a prática jornalística por esse perfil.

\footnotetext{
${ }^{1} \mathrm{O}$ conceito de externalidade tem sua origem nas ciências econômicas e designam os efeitos sobre o exterior, ou seja, são atividades que envolvem a imposição de resultantes que têm efeitos não previstos inicialmente nos projetos. Ao utilizarmos no contexto deste trabalho, nos referimos a resultantes ou arranjos derivados de um contexto midiático ou cadeia produtiva.

${ }^{2}$ É interessante perceber que até uma organização de fotojornalismo, como o VISA Pour L'Image, vinculada ao modelo editorial da fotografia de imprensa e que organiza o tradicional Festival Internacional de Fotojornalismo, realizado anualmente em Perpignan, sul da França, abriu desde o ano de 2009 uma premiação exclusiva para ensaio na web, ou seja, premiar materiais exclusivamente publicados online.

${ }^{3} \mathrm{O}$ assunto foi tema da matéria principal da revista Photo, edição de janeiro de 2011. (GREGOIRE, 2011, p.20).

${ }^{4}$ Disponível em: http://flattr.com/, http://www.thecollectivepublishinghouse.com/, http:// emphas.is/
} 
Outra externalidade é a que permite a concepção da cooperação como eixo norteador da cadeia produtiva, como no caso dos coletivos. Com nítidas influências da cultura de redes, esses agrupamentos de fotógrafos diferenciam-se de outros modelos, pois, entre diversas características, incorporam novas práticas ao processo fotográfico. É uma articulação possível, que aponta para os eixos de uma produção cooperada; trata-se de um trabalho não necessariamente vinculado a estruturas clássicas de produção da notícia, como um jornal. Esse fenômeno se apresenta como elemento presente na etapa de produção permitindo, por exemplo, possibilidades de geração de conteúdo visual renovadoras no campo estético e na organização da cadeia de trabalho.

\section{Cinco hipóteses}

O que se observa, no entanto, é um conjunto de características que permite perceber de modo mais claro a categorização entre essas três etapas, bem como o seu movimento de passagem de um estágio a outro. Trabalhamos cinco hipóteses como estruturantes e que norteiam a organização da cadeia de produção do fotojornalismo em cenários digitais e de convergência.

Hipótese 1 - A base tecnológica digital compõe toda a cadeia de produção do fotojornalismo na convergência

No momento em que, para o fotojornalismo, já se consolidou a total passagem do analógico para o digital, a condição necessária inicial para se detectar um fotojornalismo convergente é perceber, primeiro: o uso generalizado dos recursos digitais em todas etapas do fluxo de trabalho, da captação das imagens - passando por dispositivos de armazenamento primários (cartões de memória); sistemas de ingestão e organização de imagens, como o photomecanic, adobe lightroom, aperture, iphoto; plataformas transmissão via rede de dados; sistemas de edição, como o 
consagrado photoshop; sistemas de bases de dados para imagem - ao sistema de distribuição e acesso e, por fim, de salvaguarda e estocagem. A interoperabilidade desses sistemas próprios à fotografia com outros sistemas e subsistemas existentes dentro de um mesmo conjunto organizacional ou empresarial, como redações, canais de televisão, internet e até mesmo rádio. Sim, fotografia em rádio. Você não leu errado! Gitner (2009, p.14), que escreve a coluna Multimedia Moments para a revista News Photographer, relata que há fotógrafos produzindo materiais para rádios e cita, inclusive, casos de contratações ${ }^{5}$. No entanto, o autor destaca que, desses mesmos fotógrafos, se exige a capacidade multimídia no tratamento de sistemas digitais e plataformas narrativas diferentes.

O que está em jogo são dois fenômenos correlatos: a possibilidade de expansão do setor fotojornalístico para outros campos da mídia, mesmo que tradicionalmente não visuais; e, no movimento oposto, a complexificação das estruturas de apresentação de conteúdos que demandam o uso da fotografia. Deste quadro, combinado com fatores culturais de imersão na realidade de conteúdos digitais vivida atualmente, derivam as outras quatro hipóteses.

Hipótese 2 - Ocorre tanto a utilização da fotografia como elemento multimídia, como a multimídia na fotografia

São dois movimentos complementares. O primeiro envolve, segundo Salaverria (2010, p.38), uma questão que atinge o jornalismo como um todo: a potencialização dos conteúdos. O pressuposto é que todas as empresas jornalísticas têm como base o negócio de produzir continuadamente um produto cultural chamado informação, no qual a fotografia de notícia não é exceção. Prosseguindo, uma reestruturação das cadeias de produção de imagem estabelece obrigatoriamente uma mudança no modo de organização e apresentação do material visual.

\footnotetext{
${ }^{5}$ No caso, esses materiais são geralmente direcionados para websites e aplicativos de rádios para plataformas móveis, como smart phones e tablets multimídia. Gitner descreve o caso da National Public Radio, dos Estados Unidos, em que a fotografia faz parte de uma estratégia multimídia da empresa para gerar materiais com diferentes métodos de abordagem e formatação.
} 
Basicamente, trata-se de combinar diversos códigos sob uma mesma base tecnológica. O conceito de multimídia teve diversas definições e aplicações nos últimos 20 anos, sendo, portanto, para o contexto deste trabalho desnecessário esmiuçar a fundo sua concepção. Esse quadro desdobra-se sobre as organizações de notícia, que criam uma necessidade progressiva de geração de publicações com conteúdos de todo o tipo. Isso demanda, quase automaticamente, a geração de grandes parcelas de conteúdos, inclusive visuais, de modo a manter ativo o apetite por essa sorte de material. Por sua vez, isso demanda uma readaptação do conjunto de saberes do fotógrafo, que tem de conceber o caráter polissêmico das prováveis inserções do seu material em diferentes contextos, como, na contrapartida, estabelece a possibilidade da multimídia se integrar ao discurso fotojornalístico.

Nesta segunda possibilidade, a internet está cheia de exemplos. Audiovisuais que incorporam ao narrar fotográfico os elementos multimídia. Os slideshows, como popularmente são chamados, podem ser entendidos com vídeos feitos a partir de imagens estáticas, num exercício de transposição e incorporação da mídia digital de modelos de apresentação precedentes. Nada de novo nisso. Mas ela também abre um leque de opções para o uso criativo de suas ferramentas. Em diversos festivais de fotografia e de fotojornalismo, como o de Perpignan, na França, esse é o modelo dominante de apresentação de ensaios, geralmente em sessões públicas, com a presença do fotógrafo. Dentro da realidade profissional dos fotógrafos de imprensa, hoje, a aceitação desse modo de articulação visual como forma resultante de um trabalho já é ponto pacífico.

Vale ainda mencionar que em 2010 o prêmio Pulitzer de fotografia foi concedido para a fotorreportagem multimídia Ian Fischer: american soldier. Este trabalho foi concebido para ser disponibilizado na web e publicado de modo sequencial, por três dias seguidos, no jornal impresso Denver Post. A autoria é múltipla: três repórteres, dois editores multimídia e um fotógrafo, Craigh Walker, acompanharam o soldado durante 27 meses, do dia 31 de maio de 2007, quando ele concluiu a High School e se alistou no exército, até sua volta para casa, dia 21 de agosto de 2009, depois de haver estado a serviço no Iraque. 
Não é um ensaio clássico, mas sim um material em multimídia, espalhado por dez vídeos, oito galerias de fotografias e uma multiplicidade de extras ${ }^{6}$. Uma interpretação ingênua da potencialidade que o ensaio fotográfico de Craig Wlaker oferece pode responder que, cada vez mais, a internet é o lugar da fotorreportagem que se renova. Não é apenas isso. O nível de articulação em multimídia só é possível devido a um conjunto de retaguardas presentes, em níveis tecnológicos e de recursos humanos, que possibilita esse patamar de desdobramentos narrativos que, inclusive, incide nos formatos tradicionais, no caso, a versão impressa do Denver Post.

O que esse exemplo mostra - como tantos outros disponíveis na $w e b$ - é que a possibilidade da multimídia tanto é o estado inovador da prática na articulação narrativa, como também prepara o terreno de circulação em plataformas múltiplas.

Hipótese 3 - A produção de fotojornalismo em modo de convergência se orienta a uma circulação em multiplataforma.

A produção multiplataforma se baseia em potencializar um mesmo núcleo de informação através de uma sucessiva distribuição em canais diferentes quanto ao modo de acesso e consumo. Trata-se de uma aceleração de fluxo de conteúdos, de maneira geral, e de uma consequente adaptação destes conteúdos ao contexto específico de cada um. A questão aqui é o entendimento de um mesmo conteúdo por diversos dispositivos. Deste modo, uma fotografia pode ser acessada via web, dispositivo móvel, tablet ou mesmo em um impresso ou programa de televisão.

Isso aponta, segundo González (2010, p.150), para a ideia que a produção orientada à multiplataforma é um dos principais objetivos presentes nas estratégias de convergência, pois as novas formas de distribuição aumentam as possibilidades de difusão e sobretudo, consumo e negócios. O que, de imediato, se traduz em maior rentabilidade possível por unidade de informação produzida e também se sincroniza com a

${ }^{6}$ Disponível em: http://photos.denverpost.com/photoprojects/specialprojects/ianfisher/ 
realidade vigente de consumo cultural. Esta hipótese pode traduzir-se em maior alcance, aumento de visibilidade, qualidade de apresentação e, por fim, retorno financeiro.

Percebe-se, no fotojornalismo, a existência de diversas experiências nesse sentido. O jornal britânico The Guardian edita e disponibiliza para a plataforma móvel do Ipad, em parceria com o fabricante de produtos fotográficos Canon, o produto e serviço Eye Witness. Trata-se de um resumo das fotografias mais impactantes do dia. A agência de notícias Reuters também desenvolveu um produto para Ipad no qual disponibiliza o material que está sendo editado todos os dias nas mesas de edição de fotografia da agência. O serviço Reuters Galleries disponibiliza fotografias e vídeos produzidos continuamente pela agência. No caso, dá continuidade à própria tradição, presente nas estruturas das agências, de separar conteúdo de plataforma através da formatação de serviços, conceito de trabalho que ela opera há mais de 100 anos. (SILVA JUNIOR, 2006, p.94). O jornal brasileiro O Globo e o norte-americano, The New York Times também já desenvolveram produtos para o Ipad e outras plataformas móveis.

Ao mesmo tempo em que se materializa como realidade, a produção em multiplataforma desdobra-se em duas outras hipóteses, também interrelacionadas: a polivalência, na direta medida em que as tarefas, antes repartidas por profissionais de diferentes competências, passam a compor sobre cada indivíduo; e, para concluir, a cooperação entre setores de uma mesma organização ou mesmo de empresas diferentes, de modo sistemático ou conjuntural, objetivando a geração de produtos específicos. São as duas hipóteses a seguir.

Hipótese 4 - A polivalência profissional é característica necessária a produção de fotojornalismo em modo de convergência

Em alguns livros e manuais de fotojornalismo há duas imagens recorrentes, tomadas ainda do século XIX. Uma delas, a Photographic van, nada mais que uma carroça com todos os apetrechos de laboratório e equipamentos que o fotógrafo necessitava para fazer suas coberturas 
fotográficas. A outra é a de um fotógrafo, de costas, com uma enorme mochila repleta de material para a fotografia de campo. Em breves termos, essas imagens sinalizam uma época em que o fotógrafo tinha que ter domínio sobre todos os passos da cadeia produtiva da fotografia, pelo fato de nem sempre ter disponível, em suas andanças, os materiais e métodos necessários à produção de imagens.

Retorno para o tempo presente. O que atualmente está em jogo em ter esse domínio sobre os aspetos técnicos e operacionais da atividade é a sobreposição de duas tecnologias, dois saberes: a própria fotografia e os sistemas de informação digital. Isso modifica radicalmente o perfil de quem exerce a profissão no sentido não só de dominar os procedimentos de produção, mas de acumular saberes em uma sequência lógica da evolução das tecnologias e, naturalmente, do próprio ambiente de trabalho. Destarte, para ser fotógrafo de imprensa hoje é necessário sobrepor destrezas profissionais e capacidade de adaptação a um fluxo de trabalho não somente digital, mas que, em adição, lida com gramáticas de vídeo, textuais, sonoras, de informação, além, claro, de estabelecer alternativas de interoperabilidade entre sistemas tecnológicos e rotinas de trabalho.

A polivalência passa a ser um denominador comum, nada mais que uma condição precedente e necessária para se situar no horizonte e no mercado de trabalho. Fotógrafos da linha de montagem, quer dizer, com uma única tarefa, para um único tipo de veículo, são uma espécie em extinção com seus últimos exemplares vestigiais ainda em exercício. Em um mundo multiplataforma, multimídia, o que justificaria o profissional não ser multitarefa? Contudo, se, a partir desse quadro de mudança quantitativa na capacidade operacional, for gerada uma consequência de fatores qualitativos, de condições de trabalho, jornadas mais amplas e remunerações mais baixas pelas competências adquiridas, estaríamos nos arriscando a prognosticar sobre um horizonte de externalidades laborais improcedente na história do fotojornalismo.

Hipótese 5 - A cooperação e ação em rede interconectada entre agentes integra a cadeia do fotojornalismo em cenários de convergência 
Além do caráter polivalente demandado pelo quadro da convergência, a produção em fotojornalismo atualmente agrega a cooperação como elemento da sua cadeia produtiva. Nesta hipótese, a colaboração pode-se apresentar com diferentes configurações. Seja de modo interno, nas organizações noticiosas, ou entre organizações. No caso, esse esforço de cooperação visa aperfeiçoar o grau de cobertura de determinado evento e de acordo com o complexidade demandada.

Na própria história do fotojornalismo, há precedentes. É o caso dos grandes eventos esportivos, como copas do mundo e olimpíadas, onde um pool de fotógrafos operam na cobertura. No processo de convergência, contudo, a cooperação se caracteriza por demandar participação de recursos humanos procedentes de diferentes competências, como texto, audiovisual, som, gráficos e dados.

A cooperação se dá entre profissionais de distintas competências e de campos simbólicos diferentes. Envolve, ainda, uma planificação da cobertura para diferentes meios de modo a dosar e otimizar as competências em função de um evento ou fato específico. Neste caso, o que se gera é a necessidade de uma nova função: o coordenador de multimídia ou de multiplataforma, que distribuirá as cargas de esforço da equipe, a organização do material obtido e as ações de circulação.

\section{Desdobramentos}

Tratando-se de um percurso, o fotojornalismo, como toda gramática visual apoiada em tecnologias, está sob um processo contínuo de desenvolvimento e sucessão de fatores tanto de ordem tecnológica como na relação desses fatores com os contextos culturais e profissionais de sua aplicação. Evidentemente, as cinco hipóteses trabalhadas não estão blindadas contra as contradições embutidas no próprio processo. A incorporação de rotinas diferentes à cadeia produtiva do jornalismo em face aos novos cenários gera, de imediato, algumas externalidades que iremos desenvolver. 
Neste sentido, retomando a hipótese 1, na qual a base tecnológica digital compõe toda a cadeia de produção do fotojornalismo na convergência, isso não significa necessariamente abandonar o capital formativo, histórico e de procedimentos incorporados à rotina do fotojornalismo nos mais de cem anos de percurso pré-convergente.

Tão pouco pode-se pensar o fotojornalismo apenas à mercê dos desenvolvimentos tecnológicos e das pressões do mercado. O próprio surgimento de alternativas de financiamento como o crowdfunding e o surgimento dos coletivos fotográficos parecem nitidamente alternativas de escape a essa dualidade, sem, contudo, serem estratégias conflitivas com o modelo estabelecido nas redações.

Em adição, a convergência na fotografia de imprensa se junta como mais uma incorporação de elementos já aceitos na vida cotidiana, tais como as redes sociais, os novos hábitos de acesso e consumo de conteúdo, as tecnologias móveis, a cultura colaborativa etc. É um fenômeno complexo como um todo e que tem que ser considerado enxergando o cenário de fundo e não apenas o fotojornalismo ou, pior, como aponta Machado (2010, p.17), apenas como uma alternativa de corte de custos na cadeia produtiva.

Retomando a hipótese 2, na qual ocorre tanto a utilização da fotografia como elemento multimídia, como a multimídia na fotografia, o limite que se impõe, nesse viés, é perceber apenas as possibilidades dadas nessa relação sob uma visão unilateral do processo. Ou seja, transportar a fotografia para a lógica do audiovisual, gerando um híbrido que é mais uma fotografia em movimento do que uma combinação efetiva de signos ou, sobretudo, a possibilidade de se articular uma narrativa a partir de uma perspectiva que seja fotojornalística. Nesse ponto, a história do fotojornalismo também tem precedentes.

Cartier-Bresson, Robert Capa, Robert Frank, Raymond Depardon, apenas para citar exemplos mais consagrados, foram fotógrafos que desenvolveram projetos em cinema. Mais que isso, foram realizadores que levaram para o cinema a perspectiva e modo de ver as coisas que tinham desenvolvido na fotografia. No preciso momento em que a convergência também aponta para os dispositivos - e câmera de fotografar 
também é de gravar vídeo -, cabe perceber um fato curioso: grande parte dos fotógrafos que passa a realizar filmes, geralmente exercita o gênero documental. Mais que uma opção, trata-se de uma sintonia com uma leitura da realidade.

Não é a simples mudança de suporte que gera condição suficiente para a incorporação de saberes necessários à articulação em uma nova linguagem. Em outros termos, os desafios da sobreposição entre fotografia e multimídia demandam um processo de aprendizagem de modo a sanar o profundo desconhecimento que as possibilidades da multimídia podem oferecer ao universo da fotografia.

Quanto à hipótese 3 - a produção de fotojornalismo em modo de convergência se orienta a uma circulação em multiplataforma -, o que se desdobra, neste sentido, é a possibilidade de relativa perda da autonomia de produção em troca de uma produção automatizada, dada pelos sistemas de formatação e automação de conteúdos assente em bases de dados. Há que se ter em mente que na distribuição multiplataforma nem sempre é possível replicar os contextos culturais locais da recepção do material. Há que se considerar o duplo jogo de preservar a integridade do que se narra, nos seus vínculos culturais, como, na contrapartida, contextualizar e considerar com o devido cuidado a incorporação das matrizes culturais envolvidas na circulação.

Análogo a este problema, é a necessidade de elaborar conteúdos visuais com capacidade de transitar em diferentes plataformas. Os aspectos culturais e tecnológicos de uma produção em multiplataforma pressupõem um conjunto diversificado de códigos e formas, por vezes isolados e distanciados do conjunto de experiências que originou determinado projeto fotográfico. No caso específico desta hipótese, nada garante que a adoção de métodos estáveis em um determinado conjunto de dispositivos - que corresponde também a uma determinada cultura - obtenha êxitos de modo automático.

A respeito da hipótese 4, na qual a polivalência profissional é uma característica necessária à produção de fotojornalismo em modo de convergência, há que se ter claro que em um horizonte multimídia e multiplataforma a demanda natural é por profissionais multitarefa. $\mathrm{Na}$ 
prática, além de um conjunto de competências expandido para lidar com diversas rotinas, sistemas e subsistemas, o que se gera é uma acumulação de compromissos e responsabilidades pelos quais, nem sempre, o profissional recebe a devida compensação. A sobrecarga de funções, sem necessariamente haver contrapartidas, a partir do momento em que se coloca como objetivo principal da organização a cadeia produtiva, é fator insuficiente para garantir o desenvolvimento de uma estratégia como um todo. Assumir a polivalência como recurso de redução de custos compromete a sustentação da convergência, pois gera desníveis entre a articulação criativa das diversas áreas envolvidas, como a tecnológica, profissional e corporativa.

Por fim, a hipótese 5, que prevê que a cooperação e ação em rede interconectada entre agentes integra a cadeia do fotojornalismo em cenários de convergência, aponta para a possibilidade de potencialização de ganhos no processo, através de um aperfeiçoamento da sinergia entre os meios, perspectivas de trabalho, possibilidades de financiamento e, obviamente, dos ganhos indiretos de uma produção em escala e articulada. No entanto, o modelo pede uma necessária coordenação de produção de modo a estabelecer uma rotina em modelos descentralizados e autônomos com objetivos em comum. Não é, nem de longe, nem de perto, tarefa fácil.

\section{Considerações finais}

Em linhas gerais, as cinco hipóteses trabalhadas neste texto apontam para os pontos de articulação da cadeia produtiva do fotojornalismo com o fenômeno múltiplo, de ordem cultural e tecnológica, compreendido como convergência. Neste sentido, defendemos que a sobreposição possível entre essas esferas se faça de modo dialógico, com possibilidades, pressões, assimilações, recusas e sínteses. Refletir sobre as rupturas que o processo impõe é fazer um paralelo imediato com as próprias inovações de práticas que se colocam, como também perceber que a história do 
fotojornalismo se faz em meio a esse binômio, a essa tensão entre inovar e abandonar práticas.

Pensar a morte do jornalismo é reavivar um conjunto de argumentos viciados ou, como ironiza Francesco Zizola, fotógrafo da agência Noor, "o fotojornalismo vive morrendo". Pensar a inovação de um conjunto de rotinas oferecido pela convergência é também perceber o ciclo de surgimento, adoção, problematização, crise e abandono, próprio da organização da produção da cultura em moldes capitalistas. É pensar também que as próprias inovações têm ciclos. E que se um modelo é colocado em crise, como o da fotografia de imprensa direcionada a mercados massivos, esse mesmo modelo permite ver que a existência da fotografia de imprensa, que alimentou durante décadas uma indústria editorial massificada, correspondeu, ao seu tempo, a um conjunto de inovações que permitiu aquele estado de coisas.

A leitura das cinco hipóteses pode ser feita sobre dois prismas: um de crítica, que se orienta a perceber esse conjunto de problemas como necessariamente ameaçador da ontologia do fotojornalismo, pondo em risco de modo eminente, portanto, as categorias que o assentam no seu contrato social, de construção da realidade e da própria estabilidade dos sistemas de produção constituídos. Esta é, por exemplo, a postura de Jean François Leroy, diretor do festival Visa Pour L'image, que acontece há 22 anos na França e é considerado a "semana santa” do fotojornalismo mundial:

C'est difficile d'arrêter de parler de crise de la photographie parce qu'il est vrai qu'ajourd'hui on nous parle beaucoup dês nouveaux modeles de tablettes de lecture, de journaux électroniques, etc. mais ce n'est pás pour ça que les journaux produient à nouveau de la photo. La production est en chute libre, elle est quasi inexistante, c'est vraiment effrayant. (LEROY, 2010) ${ }^{7}$.

${ }_{7}$ Tradução livre do autor deste artigo: "É difícil parar de falar da crise na fotografia porque é verdade que hoje estamos falando muito dos novos modelos de tablets de leitura, dos jornais eletrônicos etc. Mas não é por isso que os jornais voltaram a produzir fotografia. A produção está em queda-livre, ela é quase inexistente, é verdadeiramente amedrontador." 
O segundo prisma se orienta a perceber que o fotojornalismo, no seu baile com a convergência, mantém a capacidade de se moldar às circunstâncias, adquirindo gramáticas, articulações produtivas e gerando produtos, como, aliás, sempre fez. Perceber esse lado como articulação inovadora não corresponde a uma visão ingênua do processo. Como contraponto à postura de Leroy, vale mencionar o que ocorre nos Estados Unidos. Patrocinado pela prestigiada NPPA (National Press Photographers Association), acontece, anualmente, desde 2008, o evento intitulado Convergence, um conjunto de palestras, treinamentos e mesas redondas versando, exatamente, sobre a questão da convergência no fotojornalismo. O programa do evento ${ }^{8}$ permite ver que o teor dos conteúdos versam, prioritariamente, sobre multimídia e fotografia, plataformas móveis, gerenciamento de redações multimídia, uso de vídeo conjugado à fotografia, fluxo de trabalho digital, organização de rotinas.

As duas visões - a de Leroy e a do seminário Convergenceestão separadas pelo Atlântico e pelo prisma de leitura histórica do processo. Analogicamente, é como se duas pessoas estivessem no vagão de um trem indo para o mesmo destino, porém cada uma olhando por um lado diferente da janela. São paisagens, portanto, diferentes.

Em nossa perspectiva, o fotojornalismo anda mal porque a própria imprensa está em crise. Preferimos acreditar que o fotojornalismo, como modo de discurso, continua ativo e criativo. Exemplos como American soldier, e tantos outros existentes na web e em plataformas móveis e distintas, ilustram que as cinco hipóteses aqui desenvolvidas podem ser articuladas na cadeia produtiva. Com capacidade de achar saídas e articulações inovadoras, o fotojornalismo continua se moldando às circunstâncias e aos constrangimentos de seu histórico percurso e tira disso as articulações que oferecem respostas ao que está colocado e problematizado neste texto.

${ }^{8}$ Disponível em: http://www.nppa.org/professional_development/workshops_and_seminars/ convergence/2010/schedule/ 


\section{Referências}

AZOULAY, Ariella. The civil contract of photography. New York: Zone Books, 2010.

BAPTISTA, Eugênio Sávio Lessa. Fotojornalismo digital no Brasil: a imagem na imprensa da era pós-fotografia. 2000. Dissertação (Mestrado em Comunicação e Cultura) - Universidade Federal do Rio de Janeiro, Rio de Janeiro.

CAFFIN, Charles H. La fotografía como una de las bellas artes [1901]. In: FONTCUBERTA, Joan. Estética fotográfica. Barcelona: Gustavo Gilli, 2003.

CORRÊA, Edson Luiz Scain. O impacto das novas tecnologias no fotojornalismo: do Dakroom ao Lightroom - o caso Zero Hora. 2001. Dissertação (Mestrado em Comunicação e Semiótica) Pontifícia Universidade Católica de São Paulo, São Paulo.

FERREIRA, Soraya Venegas. Do testemunhal ao virtual: 40 anos de fotojornalismo carioca. 2002. Tese (Doutorado em Comunicação) Universidade Federal do Rio de Janeiro, Rio de Janeiro.

FONTCUBERTA, Joan. El beso de Judas: fotografia y verdad. Barcelona: Gustavo Gilli, 1997.

. La camara de Pandora: la fotografi@ después de la fotografia. Barcelona: Gustavo Gilli, 2010.

GIACOMELLI, Ivan Luiz. Impacto da fotografia digital no fotojornalismo diário: um estudo de caso. 2000. Dissertação (Mestrado em Engenharia de Produção) - Universidade Federal de Santa Catarina, Florianópolis. 
GITNER, Seth. Making pictures for radio. News Photographer Magazine, n. 688, Apr. 2009.

GREEN, David ¿Qué ha sido de la fotografia? Barcelona: Gustavo Gilli, 2007.

GREGOIRE, Abbé. La revolution Emphas.is. Photo Magazine, n.476, Jan./Fev 2011.

JENKINS, Henry. Cultura da convergência. São Paulo: Aleph, 2008.

LEROY, Jean François. Conversations avec Jean François Leroy, recueillis par MENGUET, L. In: FESTIVAL INTERNATIONAL DU PHOTOJOURNALISME VISA POUR L'IMAGE - PERPIGNAN. Union Européenne: Editions Snoeck, 2010.

LISTER, Martin. La imagen fotográfica en la cultura digital. Barcelona: Paidós, 1997.

MACHADO, Elias. Cinco teses equivocadas sobre o ensino em tempos de convergência. In: MACHADO, Elias; TEIXEIRA, Tattiana (Org.). Ensino de jornalismo em tempos de convergência.

Rio de Janeiro: E-papers, 2010.

MITCHELL, William. The reconfigured eye: visual truth in the post photographic era. Cambridge: Mit Press, 1994.

RITCHIN, Fred. After photography. New York: W. W. Norton, 2010.

. In our own image: the coming revolution in photography. New York: Aperture Foundation, 1990. 
SALAVERRIA, Ramón. Estructura de la convergencia. In:

LÓPEZ GARCÍA, Xosé; PEREIRA FARIÑA, Xosé (Ed.)

Convergencia digital: reconfiguracion de los médios de comunicación em España. Santiago de Compostella: Universidad de Santiago de Compostella, 2010.

SILVA JUNIOR, José Afonso. O fotojornalismo em tempo de convergência digital: entre algumas permanências e outros desvios. In: ENCONTRO ANUALDA SOCIEDADE BRASILEIRA DE PESQUISA EM JORNALISMO, 6., São Bernardo do Campo, 2008. Anais... São Bernardo do Campo: SBPJOR, 2008.

. Uma trajetória em redes: modelos e características operacionais das agências de notícias. Das origens às redes digitais: com estudo de caso de três agências de notícias. Tese (Doutorado em Comunicação) - Faculdade de Comunicação, Universidade Federal da Bahia: Salvador, 2006. 